\title{
Pamuk Küspesinin Sıva Harcı İçerisinde Agrega Olarak Kullanılabilirliğinin Araştırılması
}

\author{
Yusuf Tahir ALTUNCI*1(D), Cenk ÖCAL2 ${ }^{2}$ (D) \\ ${ }^{1}$ Isparta Uygulamalı Bilimler Üniversitesi, Teknik Bilimler MYO, İnşaat Bölümü, 32260, Isparta, Türkiye \\ ${ }^{2}$ Isparta Uygulamalı Bilimler Üniversitesi, Teknoloji Fakültesi, İnşaat Mühendisliği Bölümü, 32260, Isparta, \\ Türkiye
}

\section{Anahtar Kelimeler} Pamuk küspesi, Siva harcl, Kuru birim yoğunluk, Mekanik özellik, Isıl iletkenlik.

\begin{abstract}
Özet: Bu çalışmada, CEM IV 32.5 N tipi çimento kullanarak, pamuk küspesi (0-2 mm) CEN standart kum yerine $\% 0, \% 1, \% 2, \% 3$ ve $\% 5$ oranlarında hacimce ikame edilerek su/bağlayıcı oranı 1 olan TS EN 998-2 standardına göre sıva harçları üretilmiștir. Elde edilen sıva harcı numunelerinde, pamuk küspesinin sıva harcı performans özelliklerine etkisi belirlenmiştir. Bu amaçla TS EN 998-1 standardına göre yapılması zorunlu olan; kuru birim yoğunluk, 28 günlük basınç dayanımı ve ısıl iletkenlik deneylerine ek olarak yayılma tablası yayılma çapı ve 28 günlük eğilme dayanımı deneyleri yapılmıştır. Çalışmanın sonucunda; yayılma tablası yayılma çapı değeri 25 cm'nin üzerinde olan, $1.751 \mathrm{~g} / \mathrm{cm}^{3}-1.796 \mathrm{~g} / \mathrm{cm}^{3} \mathrm{kuru}$ birim yoğunluğu aralığında, 1.98 MPa-2.23 MPa eğilme dayanımı aralığında 9.44 MPa-9.9 MPa (CS IV) basınç dayanımı aralığında ve $0.365 \mathrm{~W} / \mathrm{mK}-0.603 \mathrm{~W} / \mathrm{mK}$ ısıl iletkenliği aralığında olan pamuk küspesi ikameli sıva harçları elde elde edilmiştir. Isıl iletkenliğin önemli olmadığı yüzeylerde pamuk küspesinin sıva harcı içerisinde hacimce $\% 5$ oranına kadar agrega olarak kullanılmasında bir sakınca görülmemekle birlikte malzemenin sürdürülebilirlik açısından, uzun süreli performans özelliklerinin ve fayda-ekonomik katkı analizlerinin de yapılmasının faydalı olacağı düşünülmektedir.
\end{abstract}

\section{Investigation of the Usability of Cotton Pulp as Aggregate in Plaster Mortar}

\section{Keywords}

Cotton pulp,

Plaster mortar,

Dry density,

Mechanical features,

Thermal conductivity.

\begin{abstract}
In this study, through using CEM IV $32.5 \mathrm{~N}$ type cement, the cotton pulp $(0-2 \mathrm{~mm})$ was substituted by volume in $0 \%, 1 \%, 2 \%, 3 \%$ and $5 \%$ rates instead of CEN standard sand, and plaster mortars were produced according to the TS EN 9982 standard whose water/binder ratio is 1 . In the plaster mortar samples obtained, the effect of cotton pulp on the performance features of the plaster mortar was determined. For this purpose, in addition to dry unit density, 28-day compressive strength and thermal conductivity tests, spreading table radius and 28-day bending strength tests were performed according to the TS EN 998-1 standard, which is compulsory to perform. As a result of the study; cotton pulp-substituted plaster mortars were obtained with flow table spreading diameter above $25 \mathrm{~cm}$, in the range of dry density of $1.751 \mathrm{~g} / \mathrm{cm}^{3}-1.796 \mathrm{~g} / \mathrm{cm}^{3}$, bending strength between 1.98 MPa-2.23 MPa, compressive strength range between 9.44 MPa-9.9 MPa (CS IV) and thermal conductivity range between $0.365 \mathrm{~W} / \mathrm{mK}-0.603 \mathrm{~W} / \mathrm{mK}$. While using cotton pulp as an aggregate up to $5 \%$ by volume within plaster mortar on surfaces where thermal conductivity is insignificant has proved to be admissible, analyzing the long-term performance characteristics and the benefits-economic profits would be useful in terms of sustainability.
\end{abstract}

\section{Giriş}

Günümüzde en çok kullanılan kompozit yapı malzemeleri harç ve betondur. Özellikle karışıma giren malzemelerin temin kolaylığı harç ve betonun popüler bir yapı malzemesi olarak kullanılmasına olanak sağlamaktadır. Harç ve betonun üretimi sırasında çeşitli endüstriyel ya da endüstriyel olmayan ürünlerin kullanılmasına yönelik birçok çalışma bulunmaktadır [1,2]. Sıva harcının da benzer şekilde özelliklerinin iyileştirilmesine yönelik; gerek çimento yerine gerekse de kum yerine alternatif malzemeler 
ikame ederek çalışmalar yapılmaya devam edilmektedir $[3,4,5,6]$. Bu alternatif malzemelerden bir tanesi de endüstriyel bir ürün olan pamuk küspesidir. Pamuk, gıda dişı en önemli ürünlerden biridir [7]. Pamuk mahsulü; pamuk, pamuk tohumu yağı ve yağı alınmış pamuk küspesi için üretilir ve hasat edilir $[7,8]$. Pamuk küspesi pamuk mahsulünün en son aşamasında yağı alınarak elde edilmekte ve bünyesinde $\mathrm{C}, \mathrm{O}, \mathrm{K}, \mathrm{Mg}, \mathrm{Cu}, \mathrm{Ca}, \mathrm{S}$ ve $\mathrm{P}$ elementlerini bulundurmaktadır.

2018/2019 döneminde ülkemizde; 2.57 milyon ton kütlü pamuk üretimi yapılarak, \%38 randıman ile 976 bin ton lif pamuk ürünü elde edilmiştir [9].

$\mathrm{Bu}$ bağlamda randıman dişı ürün olan pamuk küspesinin sıva harcı içerisinde kullanılabilirliğini araştırmak üzere CEM IV $32.5 \mathrm{~N}$ tipi çimento kullanarak, 0-2 mm elek aralığındaki pamuk küspesini CEN standart kum yerine $\% 0, \% 1, \% 2, \% 3$ ve $\% 5$ oranlarında hacimce ikame ederek su/bağlayıcı oranı 1 olan sıva harçları üretilmiştir. Harç ve beton karışımları içerisinde $\mathrm{MgO}$ ve $\mathrm{CaO}$ miktarının fazla olduğu durumlarda genleşme meydana geldiği bilindiği [10] için ikame oranında \%5 oranı aşılmamıştır. Üretilen örnekler üzerinde TS EN 998-1 Kaba ve İnce Sıva Harcı standardına göre [11] yapılması zorunlu olan; kuru birim yoğunluk, 28 günlük basınç dayanımı ve ısıl iletkenlik deneylerine ek olarak yayılma tablası yayılma ve 28 günlük eğilme dayanımı deneyleri yapılmıştır. Çalışmanın sonunda; pamuk küspesi ikameli sıva harçlarının ilgili parametreler ile olan ilişkisi irdelenmiştir.

\section{Materyal ve Metot}

\subsection{Materyal}

Pamuk küspesi ikameli sıva harcl örneklerinin hazırlanmasında $2.90 \mathrm{~g} / \mathrm{cm}^{3}$ özgül ağırlığında CEM IV $32.5 \mathrm{~N}$ tipi çimento, $0.6 \mathrm{~g} / \mathrm{cm}^{3}$ özgül ağırlığında pamuk küspesi, $2.56 \mathrm{~g} / \mathrm{cm}^{3}$ özgül ağırlığında CEN standart kumu ve su kullanılmıştır. CEN standart kumunun granülometrisi Tablo 1' de, CEM IV $32.5 \mathrm{~N}$ tipi çimentonun kimyasal özellikleri Tablo 2' de, pamuk küspesinin kimyasal özellikleri ise Tablo 3' de verilmiştir.

Tablo 1. CEN standart kumun granülometrisi

\begin{tabular}{ccccccc}
\hline El. açık. (mm) & 2.00 & 1.60 & 1.00 & 0.50 & 0.16 & 0.08 \\
\hline Küm. kal. (\%) & 0 & 9 & 30 & 70 & 86 & 98 \\
\hline
\end{tabular}

Tablo 2. Cem IV $32.5 \mathrm{~N}$ kimyasal özellikleri

\begin{tabular}{ccccccccc}
\hline $\mathrm{SiO}_{2}$ & $\mathrm{Al}_{2} \mathrm{O}_{3}$ & $\mathrm{Fe}_{2} \mathrm{O}_{3}$ & $\mathrm{CaO}$ & $\mathrm{MgO}$ & $\mathrm{SO}_{3}$ & $\mathrm{Na}_{2} \mathrm{O}$ & $\mathrm{K}_{2} \mathrm{O}$ & $\mathrm{LOI}$ \\
\hline 41.14 & 10.25 & 3.36 & 33.10 & 2.14 & 2.97 & 1.12 & 1.36 & 3.90
\end{tabular}

Tablo 3. Pamuk küspesinin kimyasal özellikleri

\begin{tabular}{cccccccc}
\hline $\mathrm{C}$ & $\mathrm{O}$ & $\mathrm{K}$ & $\mathrm{Mg}$ & $\mathrm{Cu}$ & $\mathrm{Ca}$ & $\mathrm{S}$ & $\mathrm{P}$ \\
\hline 60.5 & 36.2 & 0.85 & 0.90 & 0.30 & 0.20 & 0.20 & 0.50 \\
\hline
\end{tabular}

Pamuk küspesi (Şekil 1), 0-2 mm elek aralığında elenmiş ve sıva karışımlarında, CEN standart kum yerine $\% 0, \% 1, \% 2, \% 3$ ve $\% 5$ oranlarında hacimce ikame edilerek su/bağlayıcı oranı 1 olan sıva harçlarının üretiminde kullanılmıştır.

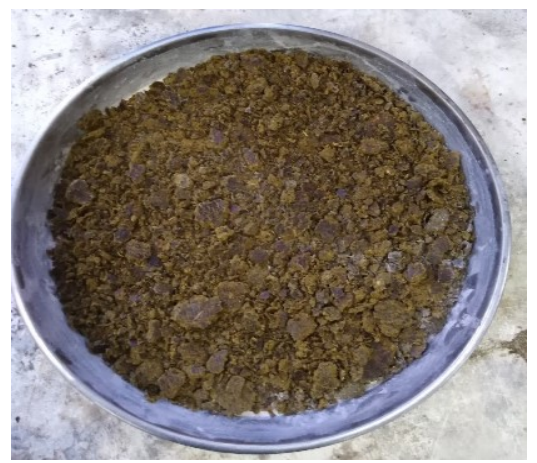

Şekil 1. Pamuk küspesi

\subsection{Metot}

Deneysel çalışmalarda bağlayıcı olarak CEM IV 32.5 N tipi çimento kullanılmış ve agrega olarak pamuk küspesi 0-2 $\mathrm{mm}$ aralığında elenerek, CEN standart kumu yerine $\% 0, \% 1, \% 2, \% 3$ ve $\% 5$ oranlarında hacimce ikame edilmiş ve su/çimento oranı 1 olarak sabit tutularak TS EN 998-2 standardına göre [12] karışımlar hazırlanmıştır. Üretilen pamuk küspesi ikameli sıva harçlarının 1 m³ karışım bilgileri Tablo 4' de verilmiştir.

Tablo 4. $1 \mathrm{~m}^{3}$ sıva harcı karışım bilgisi

\begin{tabular}{lcccc}
\hline Notasyon & $\begin{array}{c}\text { Cimento } \\
(\mathrm{kg})\end{array}$ & $\begin{array}{c}\text { Su } \\
(\mathrm{kg})\end{array}$ & $\begin{array}{c}\text { Kum } \\
(\mathrm{kg})\end{array}$ & $\begin{array}{c}\text { Pamuk } \\
\text { küspesi } \\
(\mathrm{kg})\end{array}$ \\
\hline PKO & 290 & 290 & 1484.8 & 0 \\
PK1 & 290 & 290 & 1470 & 3.5 \\
PK2 & 290 & 290 & 1455.1 & 7 \\
PK3 & 290 & 290 & 1440.3 & 10.4 \\
PK5 & 290 & 290 & 1410.6 & 17.4 \\
\hline
\end{tabular}

Pamuk küspesi ikameli sıva harcı karışımları TS EN 998-1 standardına uygun olarak hazırlanmıștır [11]. Üretim aşamasından hemen sonra TS EN 1015-3 standardına göre [13] Şekil 2' de görüldüğü gibi yayılma tablası yayılma deneyleri yapılmıștır.

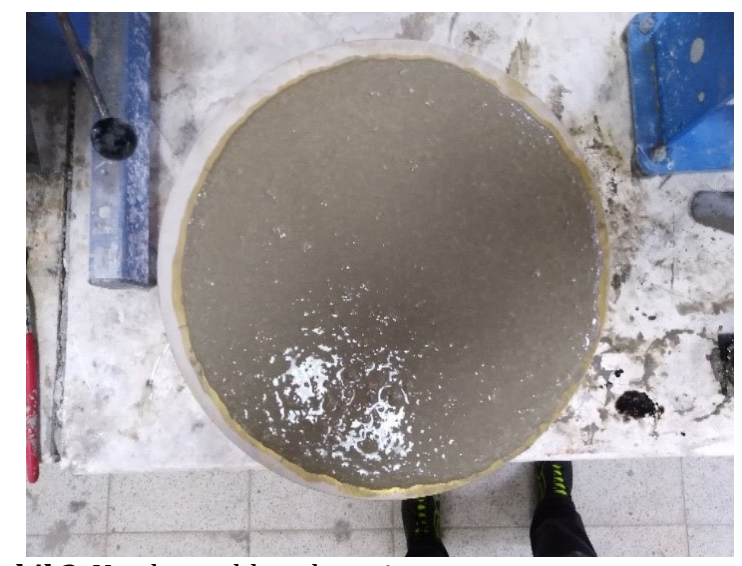

Şekil 2. Yayılma tablası deneyi 
Yayılma tablası yayılma deneyinden sonra, Hobart mikserinde kalan harç ile yayılma tablası yayılma deneyinde kullanılan taze harç, her örnek grubu için 3 'er adet olmak üzere $40 \times 40 \times 160 \mathrm{~mm}$ boyutlarındaki üçlü prizmatik kalıplara alınarak, bir gün süreyle kalıpta bekletilmiş ve üretimin ertesi günü kalıptan çlkarılarak kür havuzuna konulmuştur. Örneklerin hazırlanma aşaması görseli Şekil 3' de verilmiştir.

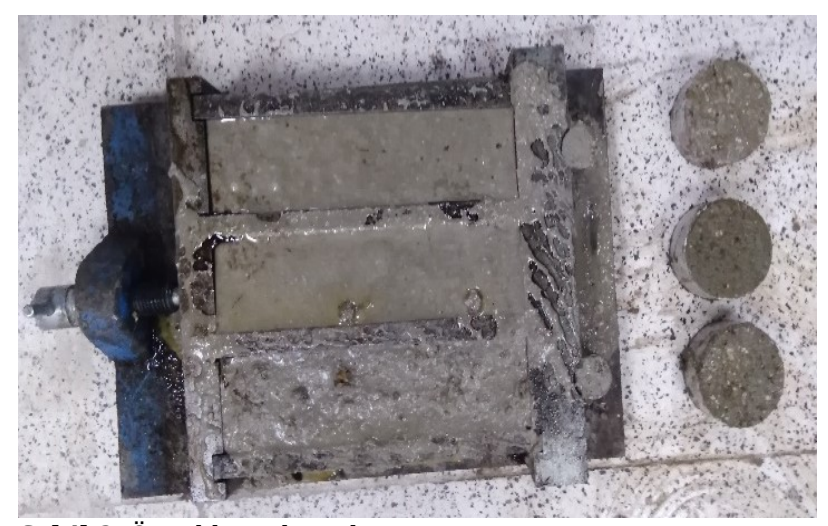

Şekil 3. Örneklerin hazırlanma aşaması

Kür işleminden sonra örneklerin, TS EN 1015-10 standardına göre [14] kuru birim ağırlıkları ölçülmüş, TS EN 1015-11 standardına göre [15] eğilme ve basınç dayanımı deneyleri ile TS EN 12664 standardına göre [16] ısıl iletkenlik deneyleri yapılmıştır. Eğilme ve basınç dayanımı deneyi görseli Şekil 4' te, ısıl iletkenlik deneyi görseli ise Şekil 5’ de verilmiştir.

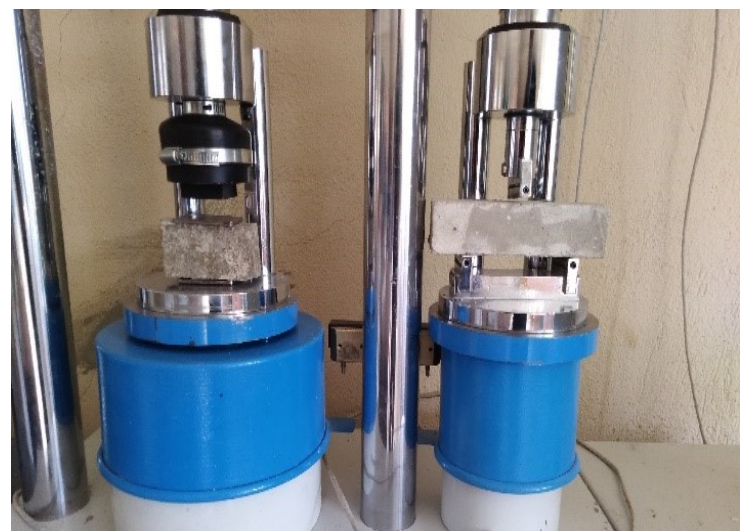

Şekil 4. Eğilme ve basınç dayanımı deneyi

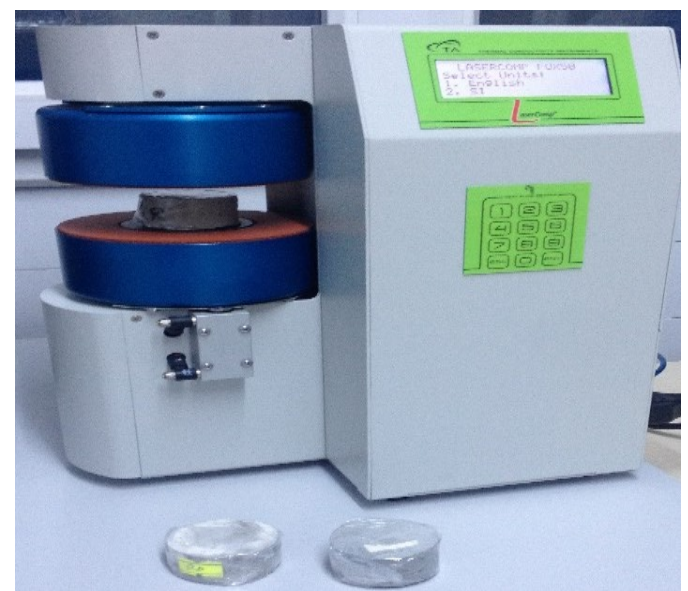

Şekil 5. Isıl iletkenlik deneyi

\section{Bulgular}

\subsection{Yayılma tablası yayılma çapı}

Şahit ve pamuk küspesi ikameli sıva harçlarının yayılma tablası yayılma çapı değerleri TS EN 1015-3 standardına göre [13] belirlenmiştir. Şahit ve pamuk küspesi ikameli sıva harçlarının yayılma tablası yayılma çapı deney sonuçları Şekil 6' da verilmiştir.

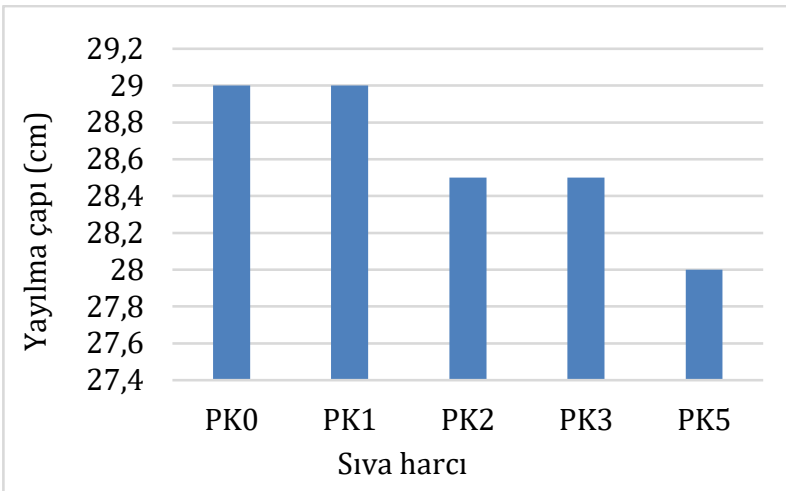

Şekil 6. Yayılma tablası yayılma değerleri

Elde edilen deney sonuçlarına göre en fazla yayılma değerine sahip örnek PKO örneği iken, en düşük yayılma değerine sahip örnek PK5 örneğidir. İkame oranı artışı ile yayılma çaplarının azaldığı gözlemlenmiştir. Bu durum, çalışmada agrega olarak kullanılan, CEN standart kum ile pamuk küspesinin su emme özelliklerinin farklı olmasından kaynaklanmaktadır. Bununla birlikte TS EN 1015-3 standardına göre [13] yayılma tablası yayılma çapları için sınır bir değer belirtilmemiştir. Ancak işlenebilirlik açısından $25 \mathrm{~cm}$ 'nin üzerinde olan bu değerlerin sıva harcı işlenebilirliği için olumlu olduğu söylenebilinir.

\subsection{Kuru birim yoğunluk}

Şahit ve pamuk küspesi ikameli sıva harçlarının kuru birim yoğunlukları TS EN 1015-10 standardına göre [14] belirlenmiştir. Şahit ve pamuk küspesi ikameli sıva harçlarının kuru birim yoğunluk deney sonuçları Şekil 7' de verilmiştir.

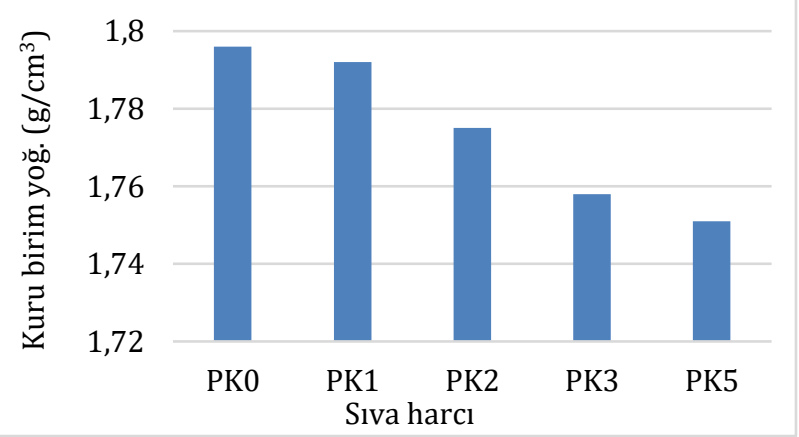

Şekil 7. Kuru birim yoğunluk değerleri

Pamuk küspesi ikameli sıva harçlarının kuru birim yoğunlukları, şahit sıva harcına göre sırasıyla PK1 için 
\%0.22, PK2 için \%1.17, PK3 için \%2.11 ve PK5 için \%2.51 oranında azalmıştır. Buna göre en yüksek kuru birim yoğunluğa $\left(1.796 \mathrm{~g} / \mathrm{cm}^{3}\right)$ sahip sıva harcı PK0 kodlu şahit sıva harcl ve en düşük kuru birim yoğunluğa $\left(1.751 \mathrm{~g} / \mathrm{cm}^{3}\right)$ sahip sıva harcı ise PK5 kodlu pamuk küspesi ikameli sıva harcıdır. Bu durum pamuk küspesi ikamesi ile sıva harcının yoğunluğunun azalması ile açıklanabilir. Literatürde yoğunluğu düşük malzemelerin agrega yerine ikame edilmesi ile birim hacim ağırlığın azaldığını gösteren çalışmalar mevcuttur $[17,18,19]$. Bu çalışmalar deney sonuçlarımızı desteklemektedir.

\subsection{Eğilme ve basınç dayanımı}

Şahit ve pamuk küspesi ikameli sıva harçlarının 28 günlük eğilme ve basınç dayanımı deneyleri TS EN 1015-11 standardına göre [15] yapılmıştır. Şahit ve pamuk küspesi ikameli sıva harçlarının eğilme dayanımı deney sonuçları Şekil 8' de, basınç dayanımı deney sonuçları ise Şekil 9’ da verilmiştir.

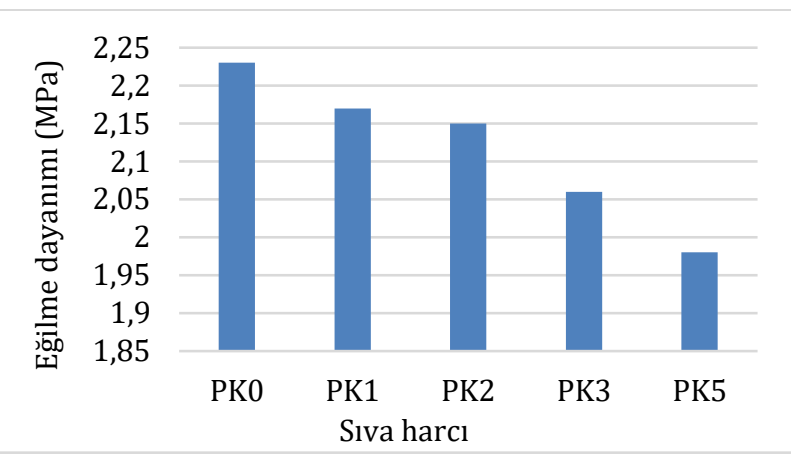

Şekil 8. Eğilme dayanımı değerleri

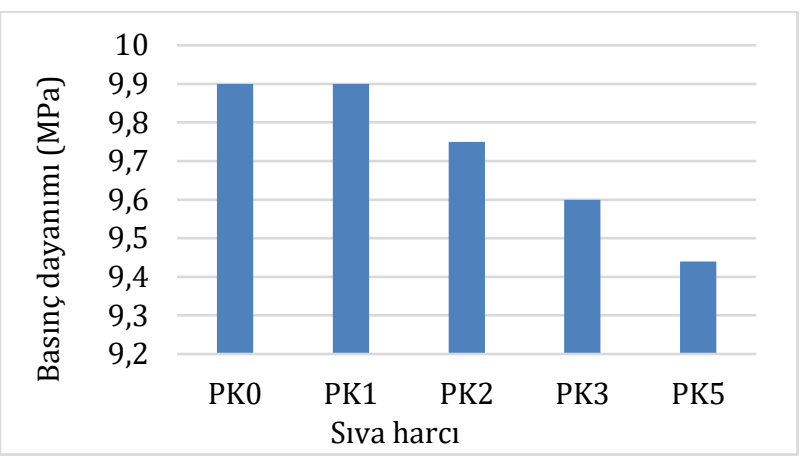

Şekil 9. Basınç dayanımı değerleri

Çalışmada 28 günlük en yüksek eğilme dayanımı 2.23 MPa ile PK0 şahit örneğine aittir. PK1, PK2, PK3 ve PK5 pamuk küspesi ikameli sıva harçlarının eğilme dayanımları sırasıyla 2.17 $\mathrm{MPa}, 2.15 \mathrm{MPa}, 2.06 \mathrm{MPa}$ ve $1.98 \mathrm{MPa}$ olarak belirlenmiştir. Eğilme dayanımı testinden çıkan örnekler üzerinde yapılan basınç dayanımı deney sonuçlarına göre, en yüksek basınç dayanımına sahip olan numune 9.9 MPa ile PK0 ve PK1 örneğidir. PK2, PK3 ve PK5 pamuk küspesi ikameli sıva harçlarının basınç dayanımları sırasıyla $9.75 \mathrm{MPa}$, 9.6 MPa ve 9.44 MPa olarak belirlenmiştir. Pamuk küspesinin kimyasal içeriği karışımın çimento ihtiyacını arttırdığı için pamuk küspesi kullanımı ile örneklerin 28 günlük eğilme ve basınç dayanımı değerlerinin azaldığı gözlemlenmiştir.

\subsection{Isıl iletkenlik}

Şahit ve pamuk küspesi ikameli sıva harçlarının ısıl iletkenlik değerleri TS EN 12664 standardına göre [16] belirlenmiştir. Şahit ve pamuk küspeli sıva harçlarının ısıl iletkenlik deney sonuçları Şekil 10' da verilmiştir.

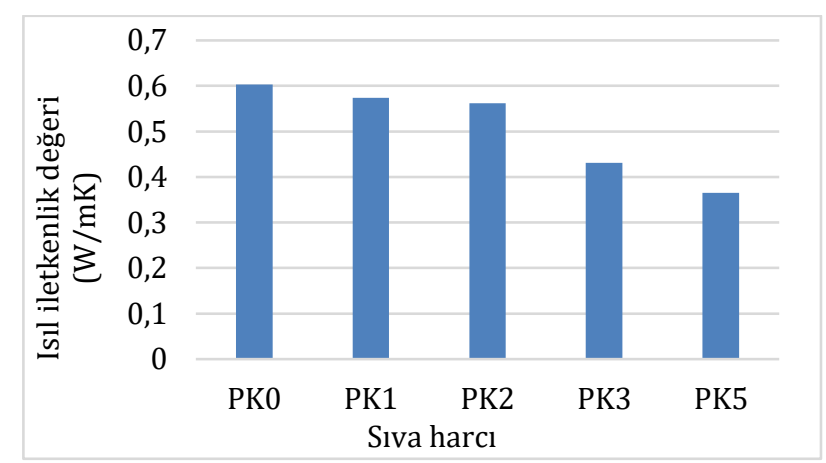

Şekil 10. Isıl iletkenlik değerleri

Yapılan deney sonucunda pamuk küspesi kullanılarak üretilen sıva harçlarının ısıl iletkenlik performansları PK5, PK3, PK2, PK1 ve PK0 şeklinde sıralanmıştır. Pamuk küspeli sıva harçlarının ısıl iletkenlik performansları, şahit sıva harcına göre sırasıyla PK1 için \%4.81, PK2 için \%6.8, PK3 için \%28.52 ve PK5 için \%39.47 oranında artmıştır. Bu artışa rağmen tüm örneklerde TS EN 998-1 standardında belirtilen [11] T1 kategorisi için $\leq 0.2 \mathrm{~W} / \mathrm{mK}$ ve T2 kategorisi için $\leq 0.2 \mathrm{~W} / \mathrm{mK}$ krtiterleri sağlanamamıştır.

\section{Tartışma ve Sonuç}

Çalışma kapsamında yapılan; yayılma tablası yayılma, kuru birim yoğunluk, 28 günlük eğilme ve basınç dayanımı ve ısıl iletkenlik deney verilerine göre aşağıdaki sonuçlar elde edilmiştir.

- Hacimce \%5 oranında pamuk küspesi kullanımı ile $25 \mathrm{~cm}$ 'nin üzerinde elde edilen yayılma tablası yayılma çaplarının, sıva harcı işlenebilirliği için olumlu olduğu söylenebilinir.

- Pamuk küspesinin hacimce \%5 oranında kullanımı ile sıva harcının kuru birim yoğunluğu ortalama olarak \%2.5 civarında azalmıştır ve bu oran sıva yapılan bir yapının tüm alanına oranlandığı zaman yapıya sıvadan kaynaklı etkiyen ağırlığı azaltmak açısından dikkate değer bir durum oluşturmaktadır.

- Üretilen sıva harcı örneklerinin, pamuk küspesi kullanım oranı artışı ile 28 günlük eğilme ve basınç dayanımları azalmıştır. Buna rağmen üretilen tüm sıva harcı örneklerinin 
dayanım sınıfı, TS EN 998-1 standardına göre [11] en üst seviye dayanım sınıfı olan CS IV kategorisinde yer almaktadır.

- Üretilen pamuk küspeli sıva harcı örneklerinin ısıl iletkenlik değerleri 0.365 $0.603 \mathrm{~W} / \mathrm{mK}$ aralı̆̆ındadır. Pamuk küspesi kullanım oranı artışı ile ısıl iletkenlik performansının iyileștiği söylenebilir. Ancak pamuk küspesi ikameli sıva harcı örneklerinin ısıl iletkenlik değerleri TS EN 998-1 standardına göre [11] yine de T1 ( $\leq$ $0.10 \mathrm{~W} / \mathrm{mK})$ ve T2 ( $\leq 0.20 \mathrm{~W} / \mathrm{mK})$ kategorisinin dışında kalmaktadır.

$\mathrm{Bu}$ bilgiler ışı̆̆ında, ısıl iletkenliğin önemli olmadığı yüzeylerde pamuk küspesinin sıva harcı içerisinde hacimce \%5 oranına kadar agrega olarak kullanılmasında bir sakınca görünmemektedir. Ancak pamuk küspesinin, hayvan yemi olarak kullanıldığı da bilindiğinden, malzemenin harç ve beton üretiminde kullanılmadan önce fayda-ekonomik katkı analizinin yapılması gerekmektedir. Bununla birlikte pamuk küspesi ikameli sıva harcı örneklerinin sürdürülebilirlik açısından, performans özelliklerinin de araştırılmasının faydalı olacağı düşünülmektedir.

\section{Etik Beyanı}

Bu çalıșmada, "Yükseköğretim Kurumları Bilimsel Araştırma ve Yayın Etiği Yönergesi" kapsamında uyulması gerekli tüm kurallara uyulduğunu, bahsi geçen yönergenin "Bilimsel Araștırma ve Yayın Etiğine Aykırı Eylemler" başlı̆̆ı altında belirtilen eylemlerden hiçbirinin gerçekleștirilmediğini taahhüt ederiz.

\section{Kaynakça}

[1] Gönen, T., Onat, 0., Cemalgil S., Yılmazer, B., Altuncı. Y. T. 2012. Beton Teknolojisi İçin Yeni Atık Malzemeler Üzerine Bir İnceleme. Yapı Teknolojileri Elektronik Dergisi, 8(1), 36-43.

[2] Yılmaz, A. 2020. Sürdürülebilirlik Açısından Mermer Atıklarının Karayolu İnşaatında Değerlendirilmesi: Ekonomik Analiz Örneği, Süleyman Demirel Üniversitesi Fen Bilimleri Enstitüsü Dergisi, 24(2), 402-410.

[3] Davraz, M., Gökçe, Y., Koru, M., Akdağ A. E. 2020. Çimento Esaslı Köpük Sıvanın Fiziksel, Mekanik ve Termal Özellikleri, Mühendislik Bilimleri ve Tasarım Dergisi, 8(1), 42-53.

[4] Nascimento, A. S., Santos, C. P., Melo, F. M. C., Oliveira, V. G. A., Oliveira, R. M. P. B., Macedo, Z. S., Oliveira, H. A. 2020. Production of Plaster Mortar With İncorporation of Granite Cutting Wastes, Journal of Cleaner Production, 265, 1-8.

[5] Haneefa, K. M., Rani, S. D., Ramasamy, R., Santhanam, M. 2019. Microstructure and
Geochemistry of Lime Plaster Mortar From a Heritage Structure, Construction and Building Materials, 225, 538-554.

[6] Baloevic, G., Radnic, J., Grgic, N., Matesan, D. 2016. The Application of a Reinforced Plaster Mortar for Seismic Strengthening of Masonry Structures, Composites Part B, 93, 190-202.

[7] He, Z., Cheng, H. N., Olanya, O. M., Uknalis, J., Zhang, X., Koplitz, B. D., He, J. 2018. Surface Characterization of Cottonseed Meal Products by Sem, Sem-Eds, Xrd and Xps Analysis. Journal of Materials Science Research, 7(1), 28-40.

[8] Liu, Y., He, Z., Shankle, M., Tewolde, H. 2016. Compositional Features of Cotton Plant Biomass Fractionscharacterized by Attenuated Total Reflection Fourier Transform İnfrared Spectroscopy, Industrial Crops and Products, 79, 283-286.

[9] Tarım ve Orman Bakanlığı. 2021. Pamuk Bülteni. https://www.tarimorman.gov.tr/BUGEM/Belgel er/M\%C4\%B0LL\%C4\%B0\%20TARIM/PAMUK \%20ARALIK\%20B\%C3\%9CLTEN\%C4\%B0.pdf (Erişim tarihi: 28/08/2021)

[10] Özdemir, İ., Koçak, Y. 2020. Pirinç Kabuğu Külü İkameli Çimentoların Fiziksel ve Mekanik Özelliklerinin Araştırılması, El-Cezerî Fen ve Mühendislik Dergisi, 7(1), 160-168.

[11] TS EN 998-1, 2017. Kâgir harcı - Özellikler Bölüm 1: Kaba ve İnce Sıva Harcı. Türk Standartları Enstitüsü, Ankara.

[12] TS EN 998-2, 2017. Kâgir harcı - Özellikler Bölüm 2: Kâgir Harcl, Türk Standartları Enstitüsü, Ankara.

[13] TS EN 1015-3, 2000. Kagir Harcl- Deney Metotları- Bölüm 3: Taze Harç Kıvamının Tayini (Yayılma Tablası İle), Türk Standartları Enstitüsü, Ankara.

[14] TS EN 1015-10, 2001. Kâgir Harcı - Deney Metotları - Bölüm 10: Sertleşmiş Harcın Boşluklu Kuru Birim Hacim Kütlesinin Tayini. Türk Standartları Enstitüsü, Ankara.

[15] TS EN 1015-11, 2020. Kagir Harcı - Deney Metotları - Bölüm 11: Sertleşmiş Harcın Basınç ve Eğilme Dayanımının Tayini, Türk Standartları Enstitüsü, Ankara.

[16] TS EN 12664, 2009. Yapı Malzemeleri ve Mamulleri - Isıl Direncin, Korumalı Tablalı Isıtıcı ve Isı Akı Ölçerin Kullanıldığı Metotlarla Tayini Isıl Direnci Orta ve Düşük Seviyede Olan Kuru ve Rutubetli Mamuller, Türk Standartları Enstitüsü, Ankara.

[17] Özün, S. 2019. Pomza'nın Fiziksel Özelliklerinin Kuru Birim Hacim Ağırlığı ve Termal İletkenliği Üzerine Etkileri, Süleyman Demirel Üniversitesi Fen Bilimleri Enstitüsü Dergisi, 23(Özel sayı), 2632. 
[18] Ceylan, H., Saraç, M. S. 2006. Farklı Pomza Agrega Türlerinden Elde Edilen Hafif Betonun Sicaklık Etkisindeki Bazı Özellikleri Üzerine Bir Araştırma, Süleyman Demirel Üniversitesi Fen Bilimleri Enstitüsü Dergisi, 10(3), 413-421.
[19] Gündüz, L., Şapcı, N., Bekar M., Yorgun, S. 2006. Genleşmiş Kilin Hafif Agrega Olarak Kullanılabilirliği, Kil Bilimi ve Teknolojisi Dergisi, 1(2), 115-121. 